\title{
First-in-Man Evaluation of 2 High-Affinity PSMA-Avid Small Molecules for Imaging Prostate Cancer
}

\author{
John A. Barrett ${ }^{1}$, R. Edward Coleman ${ }^{\dagger 2}$, Stanley J. Goldsmith ${ }^{3}$, Shankar Vallabhajosula ${ }^{3}$, Neil A. Petry ${ }^{2}$, Steve Cho $^{4}$, \\ Thomas Armor ${ }^{1}$, James B. Stubbs ${ }^{5}$, Kevin P. Maresca ${ }^{1}$, Michael G. Stabin ${ }^{5}$, John L. Joyal ${ }^{1}$, William C. Eckelman ${ }^{1}$, \\ and John W. Babich ${ }^{1}$
}

\begin{abstract}
${ }^{1}$ Molecular Insight Pharmaceuticals, Inc., Cambridge, Massachusetts; ${ }^{2}$ Duke University, Durham, North Carolina; ${ }^{3}$ New York Weill Cornell Medical Center, New York, New York; ${ }^{4}$ Johns Hopkins Medical Institution, Baltimore, Maryland; and ${ }^{5}$ Radiation Dosimetry Systems, Inc., Alpharetta, Georgia
\end{abstract}

\begin{abstract}
This phase 1 study was performed to determine the pharmacokinetics and ability to visualize prostate cancer in bone, soft-tissue, and the prostate gland using ${ }^{123}$ I-MIP-1072 and ${ }^{123}$ I-MIP-1095, novel radiolabeled small molecules targeting prostate-specific membrane antigen. Methods: Seven patients with a documented history of prostate cancer by histopathology or radiologic evidence of metastatic disease were intravenously administered $370 \mathrm{MBq}(10 \mathrm{mCi})$ of ${ }^{123} \mathrm{I}-\mathrm{MIP}-1072$ and ${ }^{123} \mathrm{I}-\mathrm{MIP}-10952 \mathrm{wk}$ apart in a crossover trial design. ${ }^{123}$ I-MIP-1072 was also studied in 6 healthy volunteers. Whole-body planar and SPECT/CT imaging was performed and pharmacokinetics studied over 2-3 d. Target-to-background ratios were calculated. Absorbed radiation doses were estimated using OLINDA/EXM. Results: ${ }^{123} \mid-M I P-$ 1072 and ${ }^{123}$ I-MIP-1095 visualized lesions in soft tissue, bone, and the prostate gland within $0.5-1 \mathrm{~h}$ after injection, with retention beyond $48 \mathrm{~h}$. Target-to-background ratios from planar images averaged $2: 1$ at $1 \mathrm{~h}, 3: 1$ at $4-24 \mathrm{~h}$, and greater than 10:1 at 4 and $24 \mathrm{~h}$ for SPECT/CT. Both agents cleared the blood in a biphasic manner; clearance of ${ }^{123}$ I-MIP-1072 was approximately 5 times faster. ${ }^{123}$ I-MIP-1072 was excreted in the urine, with $54 \%$ and $74 \%$ present by 24 and $72 \mathrm{~h}$, respectively. In contrast, only $7 \%$ and $20 \%$ of ${ }^{123}$ I-MIP-1095 had been renally excreted by 24 and $72 \mathrm{~h}$, respectively. Estimated absorbed radiation doses were 0.054 versus $0.110 \mathrm{mGy} / \mathrm{MBq}$ for the kidneys and 0.024 versus $0.058 \mathrm{mGy} / \mathrm{MBq}$ for the liver, for ${ }^{123} \mathrm{I}-\mathrm{MIP}-1072$ and ${ }^{123} \mathrm{I}-\mathrm{MIP}-$ 1095, respectively. Conclusion: ${ }^{123}$ I-MIP-1072 and ${ }^{123}$ I-MIP1095 detect lesions in soft tissue, bone, and the prostate gland at as early as 1-4 $\mathrm{h}$. These novel radiolabeled small molecules have excellent pharmacokinetic and pharmacodynamic profiles and warrant further development as diagnostic and potentially when labeled with ${ }^{131}$ I therapeutic radiopharmaceuticals.
\end{abstract}

Key Words: prostate cancer; molecular imaging; prostate specific membrane antigen

J Nucl Med 2013; 54:380-387

DOI: 10.2967/jnumed.112.111203

Received Jul. 13, 2012; revision accepted Oct. 1, 2012.

For correspondence or reprints contact: John W. Babich, Molecular Insight Pharmaceuticals, Inc., 160 Second St., Cambridge, MA 02142.

E-mail: jbabich@molecularinsight.com

tDeceased.

Published online Jan. 9, 2013.

COPYRIGHT @ 2013 by the Society of Nuclear Medicine and Molecular Imaging, Inc. t was estimated that in 2012 there would be 241,740 new cases of prostate cancer diagnosed in the United States and that 28,170 men would die of the disease $(1,2)$. When detected early, and when disease is localized to the prostate gland, the 5-y survival rate is nearly $100 \%$. However, once the cancer has spread beyond the prostate, survival rates fall dramatically (2). Hence the primary goal of staging is to define the anatomic extent of the tumor and to distinguish patients with organ-confined, locally invasive, or metastatic disease. As accurate staging is critical to determining appropriate patient management, it follows that sensitive and specific localization of disease should be a vital component of staging.

Pelvic lymph node dissection represents the most accurate staging procedure for the presence of lymph node invasion in clinically localized prostate cancer (3). However, dissection is invasive and expensive and may be associated with significant morbidity. CT and MR imaging are noninvasive procedures that are commonly used for nodal staging. However, a recent meta-analysis of the diagnostic accuracy of presurgical CT or MR imaging for staging pelvic lymph nodes suggests that the value of these modalities in the staging of prostate cancer may be low (4). The low sensitivity of both techniques suggests that CT or MR imaging will likely misrepresent the patient's true status regarding nodal metastases and could lead to a suboptimal therapeutic approach (4).

Early detection of bone metastases is critical in the management of patients with high-risk prostate cancer. Newly diagnosed patients with localized disease and no metastases may benefit from radical treatment with curative intent. In contrast, most guidelines recognize that patients with bone metastases should forgo local therapy to avoid unnecessary side effects and be treated with systemic therapy instead (5). Early metastases to bone may be missed with bone scanning because this technique relies on osteoblastic activity (mineralization) rather than detection of actual tumor cells (6). A true and sensitive measure of the presence of disease in bone should lead to earlier detection of metastatic spread and a more robust measure of changes in tumor burden that could guide patient management. 
Although current imaging techniques have limitations in the diagnosis and staging of prostate cancer, new imaging approaches that can more accurately assess the status of the disease will facilitate the selection of optimal treatment and improve patient outcomes. One strategy is to use radiopharmaceuticals that specifically target an upregulated enzyme on the surface of prostate cancer cells such as prostatespecific membrane antigen (PSMA). PSMA, also known as folate hydrolase I or glutamate carboxypeptidase II, is a transmembrane 750-amino-acid type II glycoprotein that is primarily expressed in normal human prostate epithelium but is overexpressed in prostate cancer (7), including metastatic disease $(8,9)$. Because PSMA is expressed by virtually all prostate cancers and its expression is further increased in poorly differentiated, metastatic, and hormone-refractory carcinomas $(10,11)$, it is an attractive target for prostate cancer imaging and therapy. Currently, a radiolabeled antiPSMA antibody (ProstaScint [capromab pendetide]; EUSA Pharma.) is approved to detect soft-tissue metastasis and recurrence of prostate cancer. However, this antibody targets the intracellular domain of PSMA and is thought to bind mostly to necrotic cells of prostate tumors (12). Clinical trial results with the monoclonal anti-PSMA antibody J591 have shown PSMA to be a useful diagnostic and therapeutic target $(13,14)$. Although antibodies offer potential for tumor targeting, their effectiveness as diagnostic radiopharmaceuticals is limited by a long circulating half-life and poor tumor penetrability, particularly for bone metastases.

Several investigators have reported on the use of smallmolecule inhibitors of PSMA labeled with ${ }^{123} \mathrm{I}(15-17)$, ${ }^{99 \mathrm{~m}} \mathrm{Tc}(18,19),{ }^{18} \mathrm{~F}(20),{ }^{111} \mathrm{In}(21)$, and ${ }^{68} \mathrm{Ga}(22)$ with potential for imaging PSMA. In the present study, two highaffinity radioiodinated PSMA inhibitors described previously $(16,17),{ }^{123}$ I-MIP-1072 and ${ }^{123}$ I-MIP-1095, were studied in prostate cancer patients and healthy volunteers under an exploratory investigational new drug (IND) application. The aims of these early phase 1 investigations were to assess the tumor-localizing ability, pharmacokinetics, organabsorbed radiation dose, and excretion of ${ }^{123}$ I-MIP-1072 and ${ }^{123}$ I-MIP-1095.

\section{MATERIALS AND METHODS}

\section{Study Design}

All procedures described in the following studies were approved by the institutional review boards of the participating medical institutions. The first study was an open-label crossover design of 2 novel study drugs, ${ }^{123}$ I-MIP-1072 and ${ }^{123}$ I-MIP-1095, involving 7 patients with a documented history of prostate cancer by histopathology or radiologic evidence of metastatic disease with a rising level of PSA. In 1 case, metastatic disease could not be confirmed with standard radiographic imaging techniques. The sequence of study drugs was randomized. Patients with metastatic prostate cancer were invited to participate, were screened for eligibility, and provided written informed consent. After undergoing baseline examinations, the patients received the first study drug and were followed for $72 \mathrm{~h}$ to gather whole-body planar $\gamma$-camera images, blood and urine samples for assay of radioactivity, and
SPECT/CT of the pelvis. On completion of a 2 -wk washout period, the same patients were administered the second study drug and underwent the same evaluation as for the first drug. They were followed from enrollment through $2 \mathrm{wk}$ after the second test article administration to collect safety data. In the second study, ${ }^{123} \mathrm{I}-\mathrm{MIP}$ 1072 was administered to 6 healthy volunteers to evaluate pharmacokinetics, tissue distribution, excretion, safety, and organ radiation dose with a focus on uptake in the pelvis using SPECT/CT.

\section{Study Drugs}

The synthesis of MIP-1072 [(S)-2-(3- $((S)-1$-carboxy-5-(4iodobenzylamino)pentyl)ureido) pentanedioic acid] and MIP-1095 [(S)-2-(3-((S)-1-carboxy-5-(3-(4-iodophenyl)ureido)pentyl)ureido) pentanedioic acid] and radiolabeling with ${ }^{123}$ I were described previously $(16,17)$ and were performed under good-manufacturingpractice conditions. The structure and calculated $\log \mathrm{P}$ values of MIP-1072 and MIP-1095 are shown in Figure 1.

\section{I-MIP-1072 and 123I-MIP-1095 Administration}

In the first study, each patient was randomly assigned to receive $370 \mathrm{MBq}(10 \mathrm{mCi})$ of either ${ }^{123}$ I-MIP-1072 or ${ }^{123}$ I-MIP-1095 intravenously followed $2 \mathrm{wk}$ later by the second compound. The $370 \mathrm{MBq}$ dose was required to obtain robust count statistics for accurately characterizing the systemic distribution of ${ }^{123} \mathrm{I}$ as a function of time. In the second study, healthy volunteers were intravenously administered $370 \mathrm{MBq}$ of ${ }^{123} \mathrm{I}-\mathrm{MIP}-1072$. The radioactive administered dose was determined by measuring the amount of radioactivity in the syringe before and after administration with a radioisotope dose calibrator. Thyroidal uptake was blocked at 2 of the 3 study sites (4/7 patients) using inorganic iodide. In the healthy volunteer study, thyroidal blockade was not performed.

\section{Image Acquisition}

Whole-body scintigraphy was performed at $0.5,1,2,4-6,24$, and $48 \mathrm{~h}$ after injection and, in prostate cancer patients, at $72 \mathrm{~h}$. Anterior and posterior planar projections were acquired using dual-head $\gamma$-cameras equipped with low-energy high-resolution collimators. Scan velocity was incrementally slowed from 15 $\mathrm{cm} / \mathrm{min}$ at $30 \mathrm{~min}$ and $1 \mathrm{~h}$ after injection to $10 \mathrm{~cm} / \mathrm{min}$ at $2 \mathrm{~h}$ and 4-6 $\mathrm{h}$ after injection and then $3-5 \mathrm{~cm} / \mathrm{min}$ for all remaining time points. A matrix size of $256 \times 1,024$ pixels and a symmetric window of $15 \%$ centered on a $159-\mathrm{keV}$ photopeak were used for all acquisitions. A single imaging standard of approximately $18.5 \mathrm{MBq}(500 \mu \mathrm{Ci})$

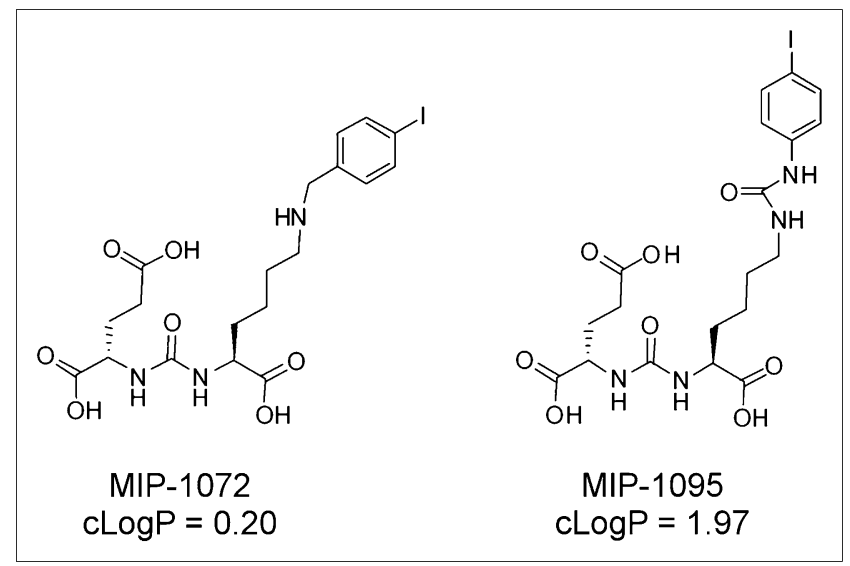

FIGURE 1. Chemical structure and calculated logP values (cLogP) of MIP-1072 and MIP-1095. 
was placed in the field of view for each whole-body acquisition to allow for decay and scan speed correction across all time points.

Tomographic SPECT of the abdomen and pelvis was performed at approximately 4 and $24 \mathrm{~h}$ after injection. When available, SPECT/CT was performed to obtain measured attenuation correction maps and to aid in anatomic localization using standard low-dose CT parameters. SPECT parameters consisted of a $360^{\circ}$ rotation, $30 \mathrm{~s}$ per stop, and a $3^{\circ}$ azimuth using a step-and-shoot technique. A matrix size of $128 \times 128$ and a symmetric window of $15 \%$ centered on a $159-\mathrm{keV}$ photopeak were used for all SPECT acquisitions. Raw SPECT data were reconstructed into 3-dimensional volumes and corrected for attenuation on a workstation (Hermes Medical Solutions) using ordered-subsets expectation maximization iterative reconstruction methods ( 3 iterations and 30 subsets) and filtered with a Butterworth filter (cutoff, 1.2; order, 5). Standard-of-care diagnostic CT of the chest, abdomen, and pelvis was obtained in patients with known prostate disease and registered to SPECT studies if a SPECT/CT scan was not acquired.

\section{Image Analysis}

Regions of interest (ROIs) were created over the imaging standard, tissues, and normal organs on each anterior and posterior planar whole-body projection to extract count data corresponding to ${ }^{123}$ I-MIP-1072 and ${ }^{123}$ I-MIP-1095 uptake. The mean count for each ROI at the first post-dose image was divided by the mean count for the whole-body ROI at the first post-dose image. The resulting ratio is expressed as a percentage and referred to as the percentage of injected activity for that organ at the initial time point. Because of poor counting statistics at the 72 -h time point ( $\sim 6$ half-lives), image analysis was performed on images acquired up to $48 \mathrm{~h}$ after injection. Tissue kinetic and mean residence time data can be found in supplemental material (available online at http://jnm.snmjournals.org).

Additional analyses of target-to-background count ratios were performed on planar and reconstructed SPECT images. For planar images, counts were obtained from fixed $4 \times 4$ pixel ROIs placed over target lesions identified by 2 independent readers and immediately adjacent to the lesion as a background. Target-to-background ratios for lesions within the SPECT field of view were calculated by obtaining counts from a circular 10-pixel ROI in the axial projection and an equal-sized ROI placed immediately adjacent as the background. Axial SPECT slices were also used to obtain prostate counts using a registered CT scan for proper anatomic localization within the prostate gland. A rectangular 20-pixel ROI was placed over the gland and immediately to the left to obtain prostate-to-background counts in patients with an intact prostate gland.

\section{Pharmacokinetics and Excretion}

Blood samples were collected from prostate cancer patients at 2-15 min and 1, 2, 4, 6, 24, 48, and $72 \mathrm{~h}$ after injection of ${ }^{123} \mathrm{I}-$ MIP-1072 or ${ }^{123}$ I-MIP-1095; urine was collected and pooled at time intervals of $0-4,4-24,24-48$, and $48-72 \mathrm{~h}$ after dosing. In the healthy volunteer study, blood and urine were collected only through $48 \mathrm{~h}$ after injection using the same time intervals. Blood and urine samples were analyzed for ${ }^{123}$ I activity using $\gamma$-well counting. The pharmacokinetic data were analyzed with WinNonlin software, version 4.1 (Pharsight). Blood and tissue concentrationtime data were computed by noncompartmental analysis (WinNonlin model 201), and pharmacokinetic parameters, such as $\mathrm{C}_{\max }$ and mean residence time, were generated. Total clearance was calculated as dose divided by area under the curve (AUC), and steadystate volume of distribution was calculated as the product of total clearance and mean residence time. Distribution half-life and elimination half-life were obtained by fitting the 2-compartment model with bolus input and first-order output (WinNonlin model 7). The rate of urinary clearance and the ${ }^{123}$ I activity recovered in the urine were also computed by noncompartmental analysis (WinNonlin model 211).

\section{Organ-Absorbed Radiation Dose Estimates}

The OLINDA/EXM software was used to estimate absorbed radiation dose to target organs $(23,24)$. The adult male model was used for all patients. The urinary bladder was assumed to be voided regularly at 4- to 8-h intervals, and the gastrointestinal transit times of the human adult male were assumed. The small-bowel and upper and lower large-intestine residence times were computed using the provided implementation of the gut transit model of publication 30 from the International Commission on Radiological Protection. The radiation doses to salivary glands and tumors were determined using spheric $S$ values as implemented in OLINDA/EXM.

\section{Safety}

Safety data were collected from treatment-emergent adverse event reports, pre- versus postinjection electrocardiograms, physical examinations, vital signs, and laboratory measurements (including clinical chemistry, hematology, and urinalysis). Adverse events were coded by the Medical Dictionary for Regulatory Activities and were summarized by occurrences and percentages of patients according to grade (National Cancer Institute Common Terminology Criteria), body system, preferred term, intensity, and causal relationship to study agent. SAS software (version 9.1; SAS Institute) was used for the safety analysis.

\section{RESULTS \\ Patients}

A summary of the diagnosis and treatment history for each patient is shown in Table 1 . All 7 patients had a documented history of prostate cancer by histopathology. Six of 7 patients had radiologic evidence of metastatic disease with rising PSA. The first study consisted of 7 men ranging in age from 53 to $86 \mathrm{y}$ with a mean PSA of $121 \mathrm{ng} / \mathrm{mL}, 6$ of whom were hormone-refractory. Three of the 7 patients had intact prostate glands. The second study consisted of 6 healthy male volunteers ranging in age from 23 to $61 \mathrm{y}$ with intact prostate glands and baseline PSA levels in the reference range.

\section{Imaging Studies and Tissue Distribution}

Typical whole-body planar and SPECT images for a patient administered ${ }^{123}$ I-MIP-1072 and ${ }^{123}$ I-MIP-1095 through $24 \mathrm{~h}$ after injection are depicted in Figure 2. Within 0.5-1 $\mathrm{h}$ after injection, metastatic bone and lymph node lesions could be detected. Uptake was also seen in the liver, bowel, kidneys, salivary glands, parotid glands, and lachrymal glands. Both the kidneys and the salivary glands are reported to express PSMA $(25,26)$. The signal in the kidneys is likely a combination of target binding and renal clearance. As the blood and soft-tissue background cleared, lesion-tobackground ratios derived from whole-body planar images increased from an average value of $2: 1$ at $1 \mathrm{~h}$ to $3: 1$ at 4 and $24 \mathrm{~h}$ after injection for ${ }^{123}$ I-MIP-1072 and ${ }^{123}$ I-MIP-1095 (Fig. 3A) but were greater than 10:1 at 4 and $24 \mathrm{~h}$ when using SPECT (Fig. 3B). 
TABLE 1

Summary of Diagnosis and Treatment History for Prostate Cancer Patients

\begin{tabular}{|c|c|c|c|c|c|c|c|c|}
\hline $\begin{array}{l}\text { Patient } \\
\text { no. }\end{array}$ & Age (y) & $\begin{array}{c}\text { Year of } \\
\text { initial } \\
\text { diagnosis }\end{array}$ & $\begin{array}{l}\text { Baseline } \\
\text { PSA } \\
\text { (ng/mL) }\end{array}$ & Prostatectomy & $\begin{array}{l}\text { Prior radiation } \\
\text { to prostate }\end{array}$ & $\begin{array}{l}\text { Prior radiation } \\
\text { to bone }\end{array}$ & $\begin{array}{c}\text { Prior } \\
\text { chemotherapy }\end{array}$ & $\begin{array}{l}\text { Prior hormone } \\
\text { therapy }\end{array}$ \\
\hline $0101^{*}$ & 66 & 2006 & $4.6^{\dagger}$ & No & No & No & None & None \\
\hline 0201 & 53 & 2005 & 30.7 & No & Yes & Yes & $\begin{array}{l}\text { Docetaxel, } \\
\text { zoledronic acid, } \\
\text { ketoconazole, } \\
\text { bevacizumab }\end{array}$ & $\begin{array}{l}\text { Bicalutamide, } \\
\text { abarelix, leuprolide, } \\
\text { diethylstilbestrol }\end{array}$ \\
\hline 0202 & 67 & 2004 & 517 & No & No & Yes & $\begin{array}{l}\text { Docetaxel, } \\
\text { mitoxantrone }\end{array}$ & $\begin{array}{l}\text { Bicalutamide, } \\
\text { leuprolide }\end{array}$ \\
\hline 0203 & 76 & 1984 & 85.3 & No & Yes & Yes & $\begin{array}{l}\text { Docetaxel, } \\
\text { bevacizumab, } \\
\text { fluorouracil }\end{array}$ & $\begin{array}{l}\text { Flutamide, nilutamide, } \\
\text { bicalutamide, } \\
\text { conjugated estrogens }\end{array}$ \\
\hline 0301 & 70 & 1996 & 15.9 & No & No & Yes & $\begin{array}{l}\text { ketoconazole, } \\
\text { hydrocortisone, } \\
\text { zoledronic acid }\end{array}$ & Leuprolide, goserelin \\
\hline 0302 & 79 & 2003 & 87.6 & Yes & No & No & $\begin{array}{l}\text { ketoconazole, } \\
\text { zoledronic acid }\end{array}$ & $\begin{array}{l}\text { Histrelin implant, } \\
\text { bicalutamide, } \\
\text { leuprolide implant }\end{array}$ \\
\hline 0303 & 86 & 1979 & 104.8 & No & Yes & No & None & $\begin{array}{l}\text { Leuprolide, } \\
\text { bicalutamide, } \\
\text { nilutamide, flutamide }\end{array}$ \\
\hline
\end{tabular}

*Patient entered study on basis of rising PSA level in presence of putative bone lesion that was not confirmed on further evaluation.

${ }^{\dagger}$ Baseline PSA level was not available. PSA was measured after evaluation of first test compound.

${ }^{123}$ I-MIP-1072 was cleared from the body more rapidly than ${ }^{123}$ I-MIP-1095. At $6 \mathrm{~h}$ after injection $62 \% \pm 5 \%$ of the injected dose remained in the body for ${ }^{123} \mathrm{I}$-MIP-1072, and by $48 \mathrm{~h}$ after injection $30 \% \pm 5 \%$ of the injected dose remained in the body. In contrast, ${ }^{123}$ I-MIP-1095 was cleared

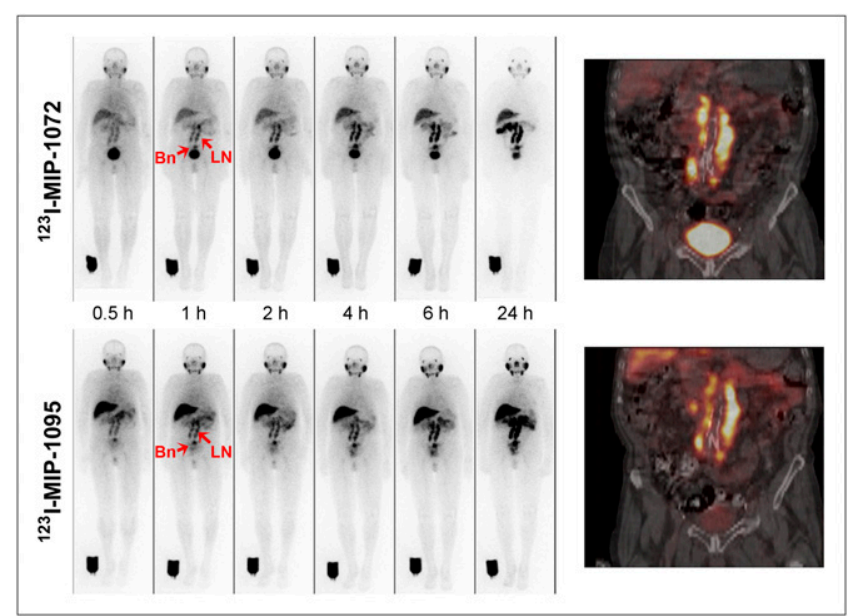

FIGURE 2. Representative anterior whole-body planar (left) and SPECT/CT (right) images of ${ }^{123}$ I-MIP-1072 and ${ }^{123 \mid-M I P-1095}$ administered at $370 \mathrm{MBq}(10 \mathrm{mCi})$ to patient with radiographically confirmed metastatic prostate cancer. Planar images are through $24 \mathrm{~h}$ after injection. Image intensity was normalized to first image using reference standard next to right leg in each image. SPECT/CT images are at $4 \mathrm{~h}$ after injection. Arrows depict localization of both compounds in confirmed lesions in paraaortic lymph nodes (LN) and bone $(\mathrm{Bn})$ of lumbar spine. from the body more slowly, resulting in increased soft-tissue uptake. At $6 \mathrm{~h}$ after injection $98 \% \pm 2 \%$ of the injected dose was still resident in the body for ${ }^{123}$ I-MIP-1095, and by $48 \mathrm{~h}$ after injection $85 \% \pm 4 \%$ of the injected dose remained in the body. In all organs, approximately 2 times greater retention was observed with ${ }^{123}$ I-MIP-1095, with a concomitant increase in tumor uptake at similar ratios.

Rapid uptake into the lesions present in the bone, lymph nodes, and prostate gland was observed with both agents. As was observed in mouse xenograft studies (17), both agents were retained in the tumors throughout the study period, with increasing uptake observed for ${ }^{123}$ I-MIP-1095 through $24 \mathrm{~h}$ after injection whereas nontarget tissues were more rapidly cleared with ${ }^{123}$ I-MIP-1072. The lesion-tobackground ratio was slightly higher for ${ }^{123}$ I-MIP-1072 than for ${ }^{123}$ I-MIP-1095, resulting from the slower totalbody clearance and greater lesion uptake observed with ${ }^{123}$ I-MIP-1095 (Figs. 3A and 3B). However, both agents had sufficient lesion uptake and background clearance to permit detection of lesions in the bone (as confirmed by bone scanning) and enlarged lymph nodes (Fig. 4) consistent with radiologic studies. Uptake in the head of the femur on bone scintigraphy (Fig. 4), likely due to degenerative changes, was not detected with either ${ }^{123}$ I-MIP-1072 or ${ }^{123}$ I-MIP-1095. Using SPECT/CT, both agents were able to detect lesions in the prostate gland at 4 and $24 \mathrm{~h}$ after injection (Fig. 5). In healthy volunteers ${ }^{123}$ I-MIP-1072 was cleared rapidly in a similar fashion to that observed in prostate cancer patients. Low uptake was observed in the prostate 
FIGURE 3. Summary of target-to-background ratios derived from whole-body planar (A) and SPECT (B) images for patients with metastatic prostate cancer. Patients were administered $370 \mathrm{MBq}(10 \mathrm{mCi})$ of 123 I-MIP-1072 (solid bar) and 123 -MIP-1095 (open bar) in crossover design. Each histogram is mean \pm SEM for 6 patients.
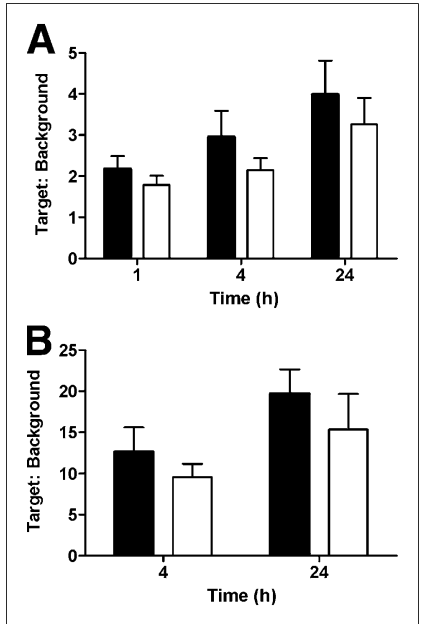

gland in healthy volunteers, a finding that supports the potential for visualization of disease in the prostate by SPECT/CT (Fig. 5).

\section{Pharmacokinetics and Excretion}

After intravenous administration, blood levels of ${ }^{123} \mathrm{I}-$ MIP-1072 and ${ }^{123}$ I-MIP-1095 declined in a biphasic fashion (Fig. 6A). ${ }^{123}$ I-MIP-1072 was rapidly cleared from the vascular compartment and moved into the extravascular space, resulting in a total-blood exposure (AUC, 0-infinity) of $0.13 \pm 0.01 \mathrm{~h} \cdot \mathrm{MBq} / \mathrm{mL}(3.5 \pm 0.3 \mathrm{~h} \cdot \mu \mathrm{Ci} / \mathrm{mL})$ and a mean residence time of $24.1 \pm 4.8 \mathrm{~h} .{ }^{123} \mathrm{I}-\mathrm{MIP}-1072$ was cleared predominantly via the kidney, with the most rapid rate observed during the first $4 \mathrm{~h}$ after injection. By $24 \mathrm{~h}$ after injection, $54 \% \pm 3 \%$ of the injected radioactivity was present in the urine (Fig. 6B). At the conclusion

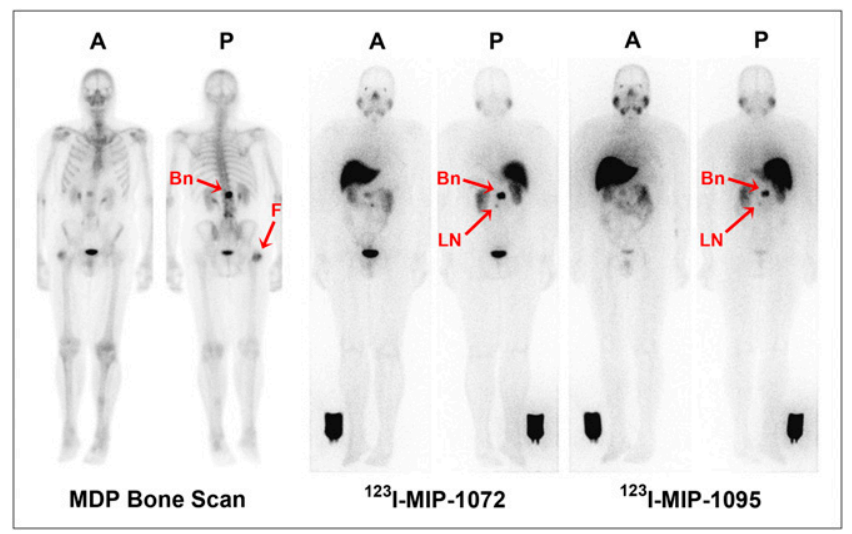

FIGURE 4. Representative anterior $(\mathrm{A})$ and posterior $(\mathrm{P})$ wholebody planar images of patient with radiographically confirmed metastatic prostate cancer who received $740 \mathrm{MBq}(20 \mathrm{mCi})$ of 99mTc-methylene diphosphonate (MDP) (left), followed by ${ }^{123}$ MIP-1072 (middle) and ${ }^{123}$ I-MIP-1095 (right) administered at 370 MBq (10 mCi). Depicted are images acquired at $4 \mathrm{~h}$ after injection. Arrows indicate detection of confirmed lesions in bone $(\mathrm{Bn})$ of lumbar spine and uptake in suggestive $7-\mathrm{mm}$ lymph node (LN). Image reference standard was placed next to right leg. Subject had previous hip replacement as demonstrated by uptake in head of right femur $(F)$ only on bone scan. of the 72 -h postinjection monitoring period, $74.3 \% \pm 3 \%$ of the injected radioactivity was excreted in the urine. Similar blood pharmacokinetic and clearance results were observed in healthy volunteers administered ${ }^{123}$ I-MIP-1072; at the last collection time point $(48 \mathrm{~h}), 59 \% \pm 6 \%$ of the injected radioactivity was excreted in the urine (Fig. 6B). Feces were not collected.

${ }^{123}$ I-MIP-1095 was cleared from the vascular compartment and moved into the extravascular space more slowly than ${ }^{123}$ I-MIP-1072, resulting in a total-blood exposure (AUC, 0 -infinity) for ${ }^{123} \mathrm{I}-\mathrm{MIP}-1095$ of $0.57 \pm 0.1 \mathrm{~h} \cdot \mathrm{MBq} / \mathrm{mL}$ $(15.3 \pm 2.8 \mathrm{~h} \cdot \mu \mathrm{Ci} / \mathrm{mL})$ and a mean residence time of $56.9 \pm$ 12.7 h. ${ }^{123}$ I-MIP-1095 was minimally cleared by the kidneys, with only $7.5 \% \pm 4.7 \%$ of the injected radioactivity present in the urine at $24 \mathrm{~h}$ and $20.3 \% \pm 8.7 \%$ of the injected radioactivity excreted in the urine at $72 \mathrm{~h}$ after injection (Fig. 6B). Feces were not collected.

\section{Radiation Dosimetry}

The absorbed radiation dose for organs was estimated in units of $\mathrm{mGy} / \mathrm{MBq}$. The complete radiation dose estimates (a standard list of 25 organs, salivary glands, total body, and effective dose and effective dose equivalent) for all subjects were used to generate the descriptive statistics shown in Table 2, with organs sorted in descending order of mean radiation dose for ${ }^{123} \mathrm{I}$-MIP-1072. For ${ }^{123} \mathrm{I}$-MIP-1072, the organ-absorbed radiation doses to the urinary bladder wall (assuming a 4.8-h void), salivary glands, and kidneys were the largest. No organ radiation dose exceeded $0.1 \mathrm{mGy} / \mathrm{MBq}$ (Table 2). For ${ }^{123}$ I-MIP-1095, the absorbed doses to the salivary glands, kidneys, and thyroid were the largest. Other than these 3 organs, no mean organ-absorbed dose exceeded $0.1 \mathrm{mGy} / \mathrm{MBq}$ (Table 2). Thyroid blockade (4/7 patients) was effective at lowering the absorbed dose to the thyroid with both compounds. ${ }^{123}$ I-MIP-1095 delivered substantially higher thyroid doses than did ${ }^{123}$ I-MIP-1072, regardless of whether blockade was used. ${ }^{123}$ I-MIP-1072 exhibited more than a $50 \%$ decrease in thyroid-absorbed radiation dose when blockade was used ( 0.050 vs. $0.030 \mathrm{mGy} / \mathrm{MBq})$, whereas ${ }^{123}$ I-MIP-1095 decreased from 0.120 to 0.084 $\mathrm{mGy} / \mathrm{MBq}$. The estimated organ-absorbed radiation dose for ${ }^{123}$ I-MIP-1072 was similar in both prostate cancer patients and healthy male volunteers. In the healthy volunteers, the thyroid dose was slightly higher since a pretreatment thyroid blockade regimen was not performed. Overall, the ${ }^{123}$ I-MIP1072 organ-absorbed radiation doses were about 30\%-60\% lower than those of ${ }^{123}$ I-MIP-1095, except for the bladder wall. However, bladder wall absorbed dose was 4.4-fold greater for ${ }^{123}$ I-MIP-1072 because of its more complete and rapid urinary clearance (Table 2). The bladder dose can be substantially reduced by encouraging consumption of fluids and more frequent voiding.

\section{Safety}

Overall, both ${ }^{123}$ I-MIP-1072 and ${ }^{123}$ I-MIP-1095 were well tolerated in this study population. Of the 7 patients receiving both ${ }^{123}$ I-MIP-1072 and ${ }^{123}$ I-MIP-1095, 3 patients 


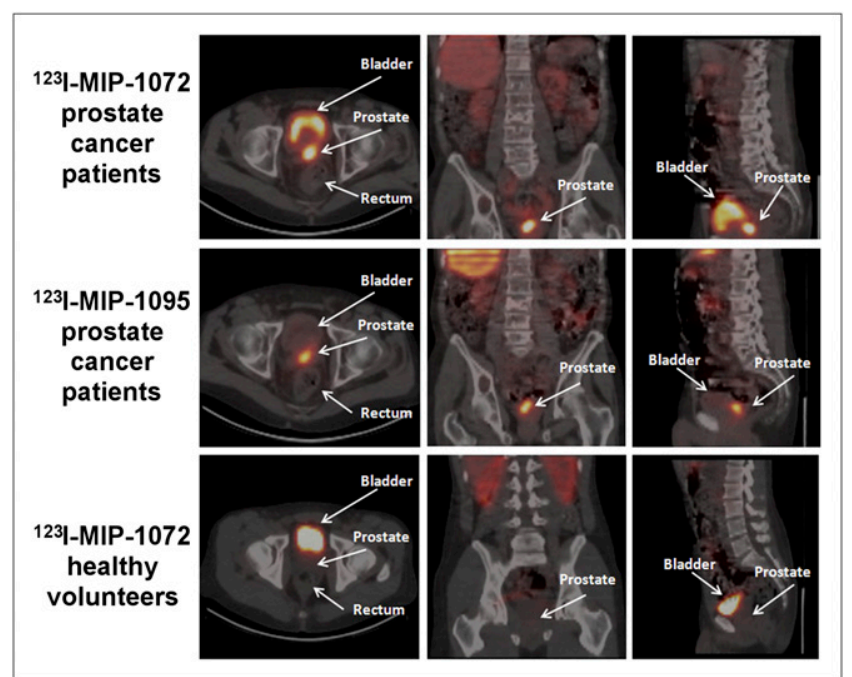

FIGURE 5. Patients with radiographically confirmed metastatic prostate cancer to whom $370 \mathrm{MBq}\left(10 \mathrm{mCi}\right.$ ) of ${ }^{123}$ I-MIP 1072 and ${ }^{123}$ |-MIP1095 were administered, and for comparative purposes, healthy volunteer to whom $370 \mathrm{MBq}$ of ${ }^{123}$-MIP 1072 were administered. Depicted are representative transaxial (left), coronal (middle), and sagittal (right) slices from reconstructed SPECT/CT at $4 \mathrm{~h}$ after injection.

reported a total of 4 treatment-emergent adverse events, all of which were mild (grade 1). The adverse events consisted of chills, constipation, insomnia, and mild injection site irritation, and all resolved without treatment. No treatmentemergent adverse events were observed in healthy volunteers receiving ${ }^{123}$ I-MIP-1072. Clinical laboratory results and physical examinations revealed no clinically relevant changes from the pre-dose to post-dose study period in prostate cancer patients or healthy volunteers.

\section{DISCUSSION}

Using the exploratory IND approach, we were able to compare the pharmacokinetics, tissue distribution, excretion, and metastatic lesion localization of 2 structurally related small molecules, ${ }^{123}$ I-MIP-1072 and ${ }^{123}$ I-MIP-1095, to select, if suitable, a candidate for further clinical development. Both agents were based on the glutamate-urea-lysine moiety modified with iodine containing aromatic substituents at the $\varepsilon$-amine of lysine, and both radiolabeled compounds were shown previously to bind with high affinity to the extracellular enzymatic domain of PSMA on prostate cancer cells $(16,17)$.

In designing an ideal imaging agent for a specific cancer, there are particular characteristics that must be considered. It is important to select a molecular target that is specific to the cancer in question and one that has consistently high expression levels per tumor cell throughout the natural progression of the disease, and ideally throughout therapy. This is particularly critical for assessing the presence of disease and changes in tumor mass and spread, whether it is low-grade localized disease or response to treatment in a patient with advanced-stage metastatic disease (27). In prostate cancer, the ability to visualize true disease burden in bone could lead to a more robust measure of changes in tumor burden that is clinically relevant to patient management. Likewise, visualization of the presence of tumor in lymph nodes that are normal by anatomic criteria would be a significant improvement in the current state of the art and lead to improved staging.

PSMA was chosen as the target since it is endogenously expressed at low levels in normal prostate, brain, kidney proximal tubules, and intestinal brush border membranes $(10,25,26,28)$. Reports indicate that increased expression of PSMA in primary prostate cancer correlates with other adverse traditional prognostic factors and independently predicts disease outcome $(11,29,30)$. Importantly, expression of PSMA is dramatically upregulated in poorly differentiated, metastatic, and hormone-refractory carcinomas (11), as well as after androgen deprivation therapy (31) and in lymph node metastases (32). The results of the present study demonstrate that targeting PSMA with both ${ }^{123}$ I-MIP-1072 and ${ }^{123}$ I-MIP1095 facilitates the detection of radiologically proven prostate cancer in bone, lymph nodes, and the prostate gland.

Ligand selection should be based on rapid uptake and persistent localization at the target site with minimal retention in nontarget tissue. Small molecules have a decisive advantage over much larger proteins given their faster rate of clearance from the blood and increased tumor permeability, which allow them to evade physiologic barriers encountered by larger molecules such as antibodies. On the basis of the pharmacokinetic parameters obtained from this study, both compounds display rapid distribution phases and blood clearance rates, with ${ }^{123}$ I-MIP-1072 being cleared from the circulation and nontarget tissues more quickly. In parallel, both compounds show rapid tumor uptake, resulting in excellent tumor-to-normal-tissue contrast on planar and SPECT scintigraphy as demonstrated in Figures 2, 4, and 5.

A particular advantage of the exploratory IND is to rapidly bring similar compounds into the clinic to confirm preclinical data. Although ${ }^{123}$ I-MIP-1072 and ${ }^{123}$ I-MIP-1095 are based on the same amino acid heterodimeric core and

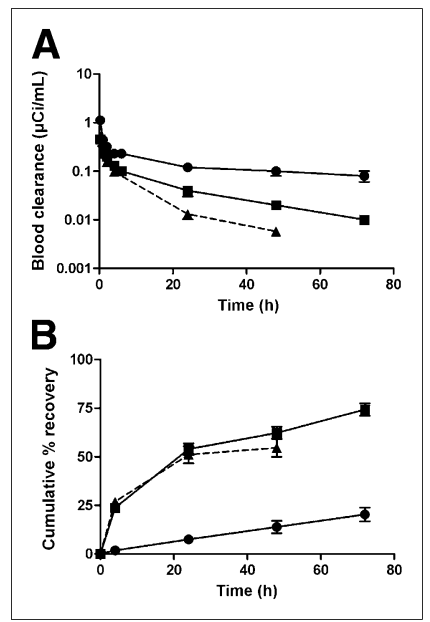

FIGURE 6. Blood clearance (A) and cumulative percentage urine recovery (B) of 123I-MIP 1072 (squares) and 123I-MIP 1095 (circles) administered at $370 \mathrm{MBq}(10$ $\mathrm{mCi}$ ) to 7 prostate cancer patients using randomized crossover design and 123/MIP-1072 (triangles) administered at $370 \mathrm{MBq}$ to 6 healthy volunteers. Depicted is mean radioactivity present in blood expressed as $\mu \mathrm{Ci} / \mathrm{mL} \pm$ SEM graphed from 0.001 $\mu \mathrm{Ci} / \mathrm{mL}(37 \mathrm{~Bq})$ to $10 \mu \mathrm{Ci} /$ $\mathrm{mL}(0.37 \mathrm{MBq})$, and cumulative recovery in urine expressed as percentage injected dose over time for each study group. 
TABLE 2

Estimates of Mean Absorbed Radiation Dose in Prostate Cancer Patients and Healthy Volunteers

\begin{tabular}{|c|c|c|c|}
\hline Target organ & $\begin{array}{l}\text { 123/-MIP-1072 prostate cancer } \\
\text { patients }(\mathrm{mGy} / \mathrm{MBq})\end{array}$ & $\begin{array}{l}\text { 123/-MIP-1095 prostate cancer } \\
\text { patients }(\mathrm{mGy} / \mathrm{MBq})\end{array}$ & $\begin{array}{l}\text { 123/-MIP-1072 healthy } \\
\text { volunteers (mGy/MBq) }\end{array}$ \\
\hline Urinary bladder wall* & 0.092 & 0.021 & 0.120 \\
\hline Salivary glands ${ }^{\dagger}$ & 0.058 & 0.160 & 0.224 \\
\hline Kidneys & 0.054 & 0.110 & 0.052 \\
\hline Distal colon & 0.046 & 0.072 & 0.036 \\
\hline Proximal colon & 0.040 & 0.066 & 0.030 \\
\hline Thyroid $\ddagger$ & 0.038 & 0.100 & 0.071 \\
\hline Liver & 0.024 & 0.058 & 0.021 \\
\hline Spleen & 0.023 & 0.047 & 0.015 \\
\hline Small intestine & 0.021 & 0.033 & 0.016 \\
\hline Osteogenic cells & 0.019 & 0.030 & 0.014 \\
\hline Heart wall & 0.016 & 0.034 & 0.009 \\
\hline Lungs & 0.015 & 0.032 & 0.010 \\
\hline Gallbladder wall & 0.014 & 0.027 & 0.011 \\
\hline Pancreas & 0.011 & 0.020 & 0.008 \\
\hline Adrenals & 0.011 & 0.020 & 0.009 \\
\hline Stomach wall & 0.009 & 0.015 & 0.007 \\
\hline Muscle & 0.007 & 0.011 & 0.006 \\
\hline Testes & 0.007 & 0.008 & 0.006 \\
\hline Red marrow & 0.007 & 0.011 & 0.005 \\
\hline Thymus & 0.006 & 0.011 & 0.005 \\
\hline Skin & 0.004 & 0.007 & 0.003 \\
\hline Brain & 0.003 & 0.006 & 0.002 \\
\hline Total body & 0.009 & 0.014 & 0.007 \\
\hline $\begin{array}{l}\text { Effective dose equivalent } \\
\quad(\mathrm{mSv} / \mathrm{MBq})\end{array}$ & 0.025 & 0.037 & 0.024 \\
\hline Effective dose (mSv/MBq) & 0.022 & 0.032 & 0.021 \\
\hline $\begin{array}{l}{ }^{\star} \text { Assumes } 4-\text { to } 8 \text {-h void. } \\
{ }^{\dagger} \text { Salivary glands represent } \\
\text { 殒 }\end{array}$ & $\begin{array}{l}\text { 7-g sphere. } \\
\text { ate cancer patients and not in }\end{array}$ & volunteers. & \\
\hline
\end{tabular}

display similar PSMA binding affinities, significantly different pharmacokinetic parameters were observed, most likely because of modest structural differences affecting hydrophobicity and protein binding. In the case of these 2 candidate molecules, target avidity is maintained while blood clearance and normal-organ clearance rates differ significantly. Such differences are seen predominately in the AUC for blood, with the more hydrophobic compound, ${ }^{123}$ I-MIP-1095, having approximately a 4-fold increase in AUC compared with ${ }^{123} \mathrm{I}$-MIP-1072. In addition, there is on average greater absolute tumor uptake with ${ }^{123}$ I-MIP-1095, although, due to nontarget tissue retention as a result of slower whole-body clearance, the signal-to-noise ratios for ${ }^{123}$ I-MIP-1072 are more attractive during the earlier time period and most practical for a diagnostic agent. Greater tumor uptake of ${ }^{123}$ I-MIP-1095 than of ${ }^{123}$ I-MIP-1072 in xenografts, coupled with prolonged elimination of ${ }^{123}$ I-MIP-1095 through a combination of renal and gastrointestinal excretion as opposed to clearance predominantly in the urine for ${ }^{123}$ I-MIP-1072, was also observed in rodent studies.

Since PSMA has been shown to be endogenously expressed in the normal prostate bed at low levels $(25,33)$, the tissue distribution, whole-body clearance, and retention of ${ }^{123} \mathrm{I}-$ MIP-1072 was also studied in healthy volunteers. On SPECT, low uptake of PSMA-targeting ${ }^{123}$ I-MIP-1072 was observed in the normal prostate gland (target-to-background ratio, $\sim 2: 1$ ) whereas 3-5 times greater uptake was seen in the prostate gland in prostate cancer patients. In view of these findings, further investigation is warranted in patients to determine whether imaging intraprostatic cancer is possible.

In the present study, both ${ }^{123}$ I-MIP-1072 and ${ }^{123}$ I-MIP-1095 localized to lesions in bone and soft tissue that correlated with radiologic evidence of metastatic disease. However, in several patients significant uptake was also observed, using planar whole-body and SPECT imaging, in lymph nodes smaller than $10 \mathrm{~mm}$, considered normal by size criteria used in crosssectional imaging such as CT and MR. Although histologic confirmation of disease in the lymph nodes is needed, these observations suggest an improvement in the sensitivity of lesion detection with molecular imaging using ${ }^{123}$ I-MIP1072 and ${ }^{123}$ I-MIP-1095 and that perhaps the future state of the art will be some combination of molecular targeting agents such as ${ }^{123}$ I-MIP-1072 and ${ }^{123}$ I-MIP-1095 and anatomic imaging.

\section{CONCLUSION}

Microdosing studies under an exploratory IND allowed for the assessment of preliminary pharmacokinetics and 
pharmacodynamics for two radioiodinated small molecules, ${ }^{123}$ I-MIP-1072 and ${ }^{123}$ I-MIP-1095, that selectively bind to PSMA with high affinity. Both compounds localized to lesions in bone and soft tissue that correlated with radiologic evidence of metastatic prostate cancer. Minimal uptake of one of these compounds ( ${ }^{123} \mathrm{I}-\mathrm{MIP}-1072$ ) was seen in the prostate gland of healthy volunteers, suggesting the possibility of visualizing disease in that organ. On the basis of the higher signal-to-background ratio, ${ }^{123}$ I-MIP-1072 was evaluated as a diagnostic agent in subsequent clinical trials, and on the basis of the prolonged tumor retention as a result of slower tissue kinetics, ${ }^{131}$ I-MIP-1095 will be evaluated clinically for radiotherapy. Hence, in this case the exploratory IND has afforded the opportunity to select both diagnostic and therapeutic radiopharmaceuticals.

\section{DISCLOSURE}

The costs of publication of this article were defrayed in part by the payment of page charges. Therefore, and solely to indicate this fact, this article is hereby marked "advertisement" in accordance with 18 USC section 1734. No potential conflict of interest relevant to this article was reported.

\section{REFERENCES}

1. American Cancer Society Web site. Cancer facts and figures. http://www.cancer. org/Research/CancerFactsFigures/index. Accessed December 20, 2012.

2. National Cancer Institute Web site. SEER stat fact sheets: prostate. http://seer. cancer.gov/statfacts/html/prost.html. Accessed December 20, 2012.

3. Aus G, Abbou CC, Bolla M, et al. EAU guidelines on prostate cancer. Eur Urol. 2005;48:546-551.

4. Hövels AM, Heesakkers RA, Adang EM, et al. The diagnostic accuracy of CT and MR in the staging of pelvic lymph nodes in patients with prostate cancer: a meta-analysis. Clin Radiol. 2008;63:387-395.

5. Heidenreich A, Aus G, Bolla M, et al. EAU guidelines on prostate cancer. Eur Urol. 2008;53:68-80.

6. Toegel S, Hoffmann O, Wadsak W, et al. Uptake of bone-seekers is solely associated with mineralisation! A study with ${ }^{99 \mathrm{~m} T c-M D P,}{ }^{153} \mathrm{Sm}-\mathrm{EDTMP}$ and ${ }^{18}$ F-fluoride on osteoblasts. Eur J Nucl Med Mol Imaging. 2006;33:491-494.

7. Ghosh A, Heston WDW. Tumor target prostate-specific membrane antigen (PSMA) and its regulation in prostate cancer. J Cell Biochem. 2004;91:528-539.

8. Israeli RS, Powell CT, Fair WR, Heston WD. Molecular cloning of a complementary DNA encoding prostate-specific membrane antigen. Cancer Res. 1993;53:227-230.

9. Horoszewicz JS, Kawinski E, Murphy GP. Monoclonal antibodies to a new antigenic marker in epithelial prostatic cells and serum of prostatic cancer patients. Anticancer Res. 1987;7:927-935.

10. Silver DA, Pellicer I, Fair WR, Heston WD, Cordon-Cardo C. Prostate-specific membrane antigen expression in normal and malignant human tissues. Clin Cancer Res. 1997;3:81-85.

11. Perner S, Hofer MD, Kim R, et al. Prostate-specific membrane antigen expression as a predictor of prostate cancer progression. Hum Pathol. 2007;38:696701.

12. Troyer JK, Beckett ML, Wright GL. Location of prostate-specific membrane antigen in the LNCaP prostate carcinoma cell line. Prostate. 1997;30:232-242.
13. Milowsky MI, Nanus DN, Kostakoglu L, et al. Vascular targeted therapy with anti-prostate-specific membrane antigen monoclonal antibody J591 in advanced solid tumors. J Clin Oncol. 2007;25:540-547.

14. Vallabhajosula S, Goldsmith SJ, Kostakoglu L, et al. Radioimmunotherapy of prostate cancer using ${ }^{90} \mathrm{Y}$ - and ${ }^{177} \mathrm{Lu}$-labeled J591 monoclonal antibodies: effect of multiple treatments on myelotoxicity. Clin Cancer Res. 2005;11(19 pt 2):7195s$7200 \mathrm{~s}$.

15. Foss CA, Mease RC, Fan H, et al. Radiolabeled small molecule ligands for prostate-specific membrane antigen: in vivo imaging in experimental models of prostate cancer. Clin Cancer Res. 2005;11:4022-4028.

16. Maresca KP, Hillier SM, Femia FJ, et al. A series of halogenated heterodimeric inhibitors of prostate-specific membrane antigen (PSMA) as radiolabeled probes for targeting prostate cancer. J Med Chem. 2009;52:347-357.

17. Hillier SM, Maresca KP, Femia FJ, et al. Preclinical evaluation of novel glutamateurea-lysine analogs that target prostate specific membrane antigen as molecular imaging pharmaceuticals for prostate cancer. Cancer Res. 2009;69:6932-6940.

18. Kularatne SA, Zhou Z, Yang J, et al. Design, synthesis, and preclinical evaluation of prostate-specific membrane antigen targeted ${ }^{99 \mathrm{~m} T c-r a d i o i m a g i n g}$ agents. $\mathrm{Mol}$ Pharm. 2009;6:790-800.

19. Lu G, Maresca KP, Hillier SM, et al. Synthesis and SAR of ${ }^{99 m} \mathrm{Tc} /$ Re-labeled small molecule prostate specific membrane antigen inhibitors with novel polar chelates. Bioorg Med Chem Lett. In press.

20. Chen Y, Pullambhatla M, Foss CA, et al. 2-(3-\{1-carboxy-5-[(6- $\left[{ }^{18} \mathrm{~F}\right]$ fluoro-pyridine3-carbonyl)-amino]-pentyl $\}$-ureido)-pentanedioic acid, [ $\left.{ }^{18} \mathrm{~F}\right] \mathrm{DCFPyL}$, a PSMAbased PET imaging agent for prostate cancer. Clin Cancer Res. 2011;17: 7645-7653.

21. Banerjee SR, Pullambhatla M, Shallal H, et al. A modular strategy to prepare multivalent inhibitors of prostate-specific membrane antigen (PSMA). Oncotarget. 2011;2:1244-1253.

22. Afshar-Oromieh A, Haberkorn U, Eder M, Eisenhut M, Zechmann CM. [ $\left.{ }^{68} \mathrm{Ga}\right]$ gallium-labelled PSMA ligand as superior PET tracer for the diagnosis of prostate cancer: comparison with ${ }^{18}$ F-FECH. Eur J Nucl Med Mol Imaging. 2012;39:10851086.

23. Stabin MG, Siegel JA. Physical models and dose factors for use in internal dose assessment. Health Phys. 2003;85:294-310.

24. Stabin MG, Sparks RB, Crowe E. OLINDA/EXM: the second generation personal computer software for internal dose assessment in nuclear medicine. $\mathrm{J} \mathrm{Nucl}$ Med. 2005;46:1023-1027.

25. Kinoshita Y, Kuratsukuri K, Landas S, et al. Expression of prostate specific membrane antigen in normal and malignant human tissue. World J Surg. 2006;30:628-636.

26. Troyer JK, Beckett ML, Wright GL Jr. Detection and characterization of prostate-specific membrane antigen (PSMA) in tissue extracts and bodily fluids. Int J Cancer. 1995;62:552-558.

27. Moyer BR, Barrett JA. Biomarkers and imaging: physics and chemistry for noninvasive analyses. Bioanalysis. 2009;1:321-356.

28. Luthi-Carter R, Barczak AK, Speno H, Coyle JT. Molecular characterization of human brain $\mathrm{N}$-acetylated alpha-linked acidic dipeptidase (NAALADase). J Pharmacol Exp Ther. 1998;286:1020-1025.

29. Marchal C, Redondo M, Padilla M, et al. Expression of prostate specific membrane antigen (PSMA) in prostatic adenocarcinoma and prostatic intraepithelial neoplasia. Histol Histopathol. 2004;19:715-718.

30. Ross JS, Sheehan CE, Fisher HA, et al. Correlation of primary tumor prostatespecific membrane antigen expression with disease recurrence in prostate cancer. Clin Cancer Res. 2003;9:6357-6362.

31. Wright GL Jr, Grob BM, Haley C, et al. Upregulation of prostate-specific membrane antigen after androgen-deprivation therapy. Urology. 1996;48:326-334.

32. Sweat SD, Pacelli A, Murphy GP, Bostwick DG. Prostate-specific membrane antigen expression is greatest in prostate adenocarcinoma and lymph node metastases. Urology. 1998;52:637-640.

33. Chuang AY, DeMarzo AM, Veltri RW, Sharma RB, Bieberich CJ, Epstein JI. Immunohistochemical differentiation of high-grade prostate carcinoma from urothelial carcinoma. Am J Surg Pathol. 2007;31:1246-1255. 